\title{
Energy Saving Potential by Using Maisotsenko-Cycle in Different Applications
}

\author{
Demis Pandelidis*, Anna Pacak and Sergey Anisimov
}

Wrocław University of Science and Technology, 50-370 Wrocław, Poland

\begin{abstract}
The Maisotsenko cycle (M-cycle) is a proven thermodynamic process which captures energy from the air, utilizing the psychometric renewable energy, available from latent heat of water evaporating into the air. In air conditioning, the M-cycle uniquely combines thermodynamic processes of heat transfer and evaporative cooling, in order to enable temperature of the product to approach ambient dew point temperature. The capturing energy from the latent heat of evaporation may be usedin electric energy generation, engine technology, water distillation with absolutely no carbon emissions. The principles of M-cycle can be used in any application which requires energy. Most popular application of the Maisotsenko cycle are the air conditioning systems; it is proven that M-Cycle can reduce the energy consumption up to $90 \%$ in comparison to traditional solutions. Besides the air conditioning systems, M-Cycle can also be used for effective water desalination, increasing the effectiveness of gas turbines and photovoltaic panels. The following paper discusses different applications of the Maisotsenko cycle and describes energy savings which can be obtained.
\end{abstract}

Publication History:

\section{Introduction}

Heat transfer is a critical process in terms of development of the civilization. Due to heat transfer, we have electricity (burning natural gas and coal), cars (burning fuel), heating and air conditioning systems in houses or even refrigerators in the kitchen. The major problem with this process is that its effectiveness is critical in terms of how much we pay for keeping our living standard. The less effective devices we use, the more money we have to spend. Natural energy existing in the air allows to create every kind of energy needed by mankind: it cools, it heats, it creates electricity (thunderstorm), it creates water (rain) and it creates a gigantic potential of power through the movement of air. Recently, humanity tries to utilize the energy of wind in wind turbines, but its approach is also incorrect from physical standpoint- the point is not to use the existing wind, the point is to recreate a mechanism which naturally creates the wind and use it for own purposes. There is only one process which allows to fully utilize the power of atmospheric air thermodynamic unbalance: this process is called the Maisotsenko cycle (M-Cycle). Evaporative cooling through the M-Cycle is commonly used in air conditioning and it becomes more and more popular in the world. The main advantage of M-Cycle technology over typical vapor-compression systems is that it utilizes significantly less electricity [1]. It is the reason why the M-Cycle devices are treated as environmental friendly solution for cooling energy production for air conditioning purposes. According to the literature the M-Cycle technology may be used also for (a) air humidification, (b) heat recovery in turbines, (c) water cooling, and (d) water distillation [2]. In this study, selected M-Cycle applications are considered to give an insight into wide implementation potential of Maisotsenko-Cycle.

\section{Cooling by Indirect Evaporative Cooling}

The M-Cycle technology allows to reach the dew point temperature of ambient air. On the other hand, typical indirect evaporative coolers (IEC) may cool the ambient air to its wet-bulb temperature. The scheme of counter-flow indirect evaporative cooler is presented in Figure 1 (a). There are two streams which are delivered to two separate channels. In wet channel there is a thin water layer in which the evaporation process takes place. The water needs to absorb the amount of heat to change phase into vapor. That is why the heat is transferred directly from the air which surrounds the water and indirectly through the heat exchanger plate from the other stream of air (product airflow). As a result, the temperature of both air streams decreases. The most important aspect of indirect evaporative coolers is that they do not have any moving parts. Unlike traditional air conditioning systems, they do not require compressors, valves and chemical refrigerants. They only need air, water and small amount of energy for the fans to pass the air through them. Therefore, they consume very low amount of energy comparing to the typical systems (this is because of effective use of heat of water evaporation).

\section{The Idea of The Maisotsenko-Cycle}

The M-cycle is a modification of indirect evaporative cooling explained in a previous section. There is one key difference. The part of the product airflow is gradually reversed to awet channel and it becomes the working airflow. It means that the air is precooled first before it enters the wet channel (Figure 2). It allows to decrease the cooling temperature limit, hence it is possible to cool the air almost to the dew point temperature of the working airflow what makes this process more effective. The M-Cycle heat and mass exchangers are commonly used in air conditioning systems. They became more and more popular because they can cool the air to lower temperatures without high electricity consumption. It is already proven that the wet-bulb effectiveness of M-Cycle devices is up to 1.80 [3] whereas for IEC it may reach the wet-bulb effectiveness equal to 1.0.

"Corresponding Author: Dr. Demis Pandelidis, Wrocław University of Science and Technology, 50-370 Wrocław, Poland; E-mail: remik71@tlen.pl

Citation: Pandelidis D, Pacak A, Anisimov S (2018) Energy Saving Potential by Using Maisotsenko-Cycle in Different Applications. Int J Earth Environ Sci 3: 159. doi: https://doi.org/10.15344/2456-351X/2018/159

Copyright: (C) 2018 Pandelidis et al. This is an open-access article distributed under the terms of the Creative Commons Attribution License, which permits unrestricted use, distribution, and reproduction in any medium, provided the original author and source are credited. 
Citation: Pandelidis D, Pacak A, Anisimov S (2018) Energy Saving Potential by Using Maisotsenko-Cycle in Different Applications. Int J Earth Environ Sci 3: 159. doi: https://doi.org/10.15344/2456-351X/2018/159

Page 2 of 5

\section{M-Cycle Applications}

\section{Cooling tower through the M-Cycle}

Cooling towers are generally used to reject waste heat to the atmosphere through the cooling water stream [4]. Providing cooled water for air conditioning systems and for power generation processes are the two most popular applications of cooling towers. The conventional cooling tower (CCT) schemes are presented in Figure 3. It has to be mentioned that they use direct evaporative cooling technique to cool the water. The ambient air contacts water directly, hence its humidity ratio increases and water temperature decreases consequently. The temperature limit to which water may be cooled in CCT is wet-bulb temperature of the ambient air.

There is a possibility to conduct the cooling of water to the dew point temperature by the M-Cycle cooling tower (MCT). Due to specific water distribution (through the package) and air flow route, using M-cycle cooling tower helps to reduce the pressure drop and consequently fan power. The performance of MCT is visualized in Figure 3.
There are two main M-Cycle cooling towers: close circuit (Figure 3 (a)) and open circuit (Figure 3 (b)). In both of them, the air is cooled sensibly before it enters the wet channel. It allows to cool the water to the dew point temperature of ambient air. Closed MCT has an additional product channel in which there is no direct contact of the air with the process fluid i.e. water or a glycol/water mixture. Working dry channel provides precooling process before working air enters working wet channel in which evaporation is realized (see Figure 4(b)). Both cooling towers were already compared with CCT by Gillian et al. [7]. Results showed that both MCTs cooled the water at lower temperature than the CCT and enabled double evaporation rate. The open circuit MCT has simple fill structure and that is why it has been analyzed by many other researchers [5].

Morsuk et al. [8] performed simulations of MCT for various ambient air operating conditions. They determined COP values of MCT which yields between 0.20 and 0.90 . There is the main advantage of MCT over CCT. When ambient air temperature increases, the COP of MCT also increases. That is why it is worth to apply MCT in hot climates. Finally, Sverdlin et al. [9] analyzed the M-Cycle cooling tower using simulation program which was validated on the basis of

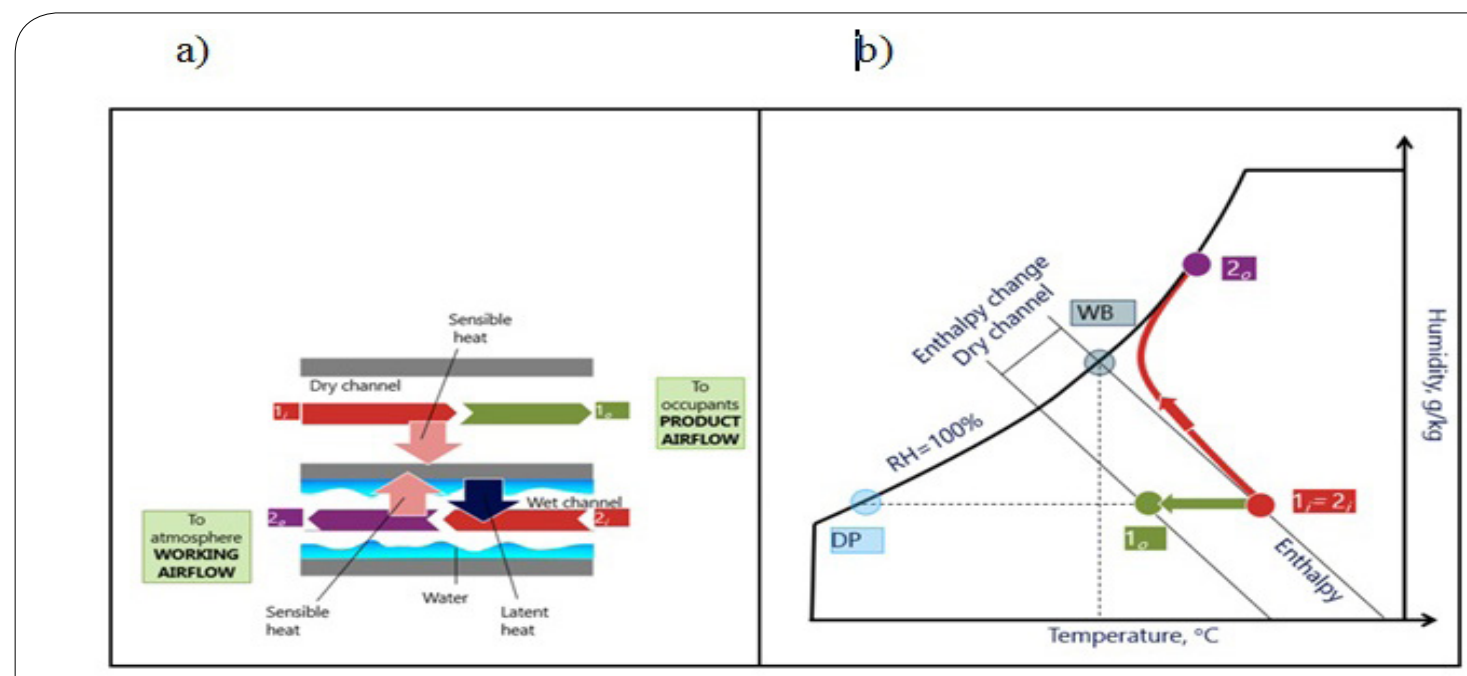

Figure 1: Indirect evaporative cooling a) Scheme. b) Psychometric chart.

a)

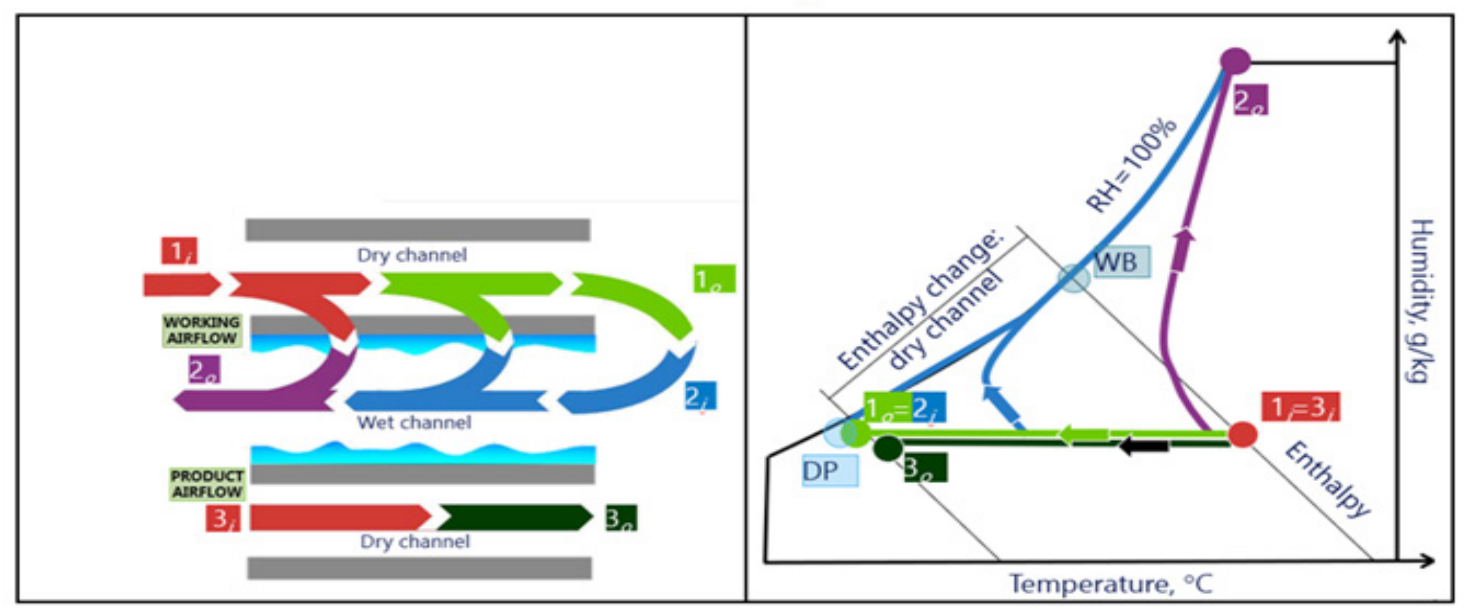

Figure 2: M-Cycle indirect evaporative cooling a) Scheme. b) Psychometric chart.
Int J Earth Environ Sci

ISSN: $2456-351 \mathrm{X}$
IJEES, an open access journal Volume 3. 2018. 159 
Citation: Pandelidis D, Pacak A, Anisimov S (2018) Energy Saving Potential by Using Maisotsenko-Cycle in Different Applications. Int J Earth Environ Sci 3: 159. doi: https://doi.org/10.15344/2456-351X/2018/159

Page 3 of 5

real field data, obtained from existing cooling towers. They confirmed that cooling towers through the M-Cycle may significantly reduce the water temperature.

\section{Distillation system through the M-Cycle}

There are many techniques of water distillation which may allow to separate pure water from salty water (desalination). The most popular

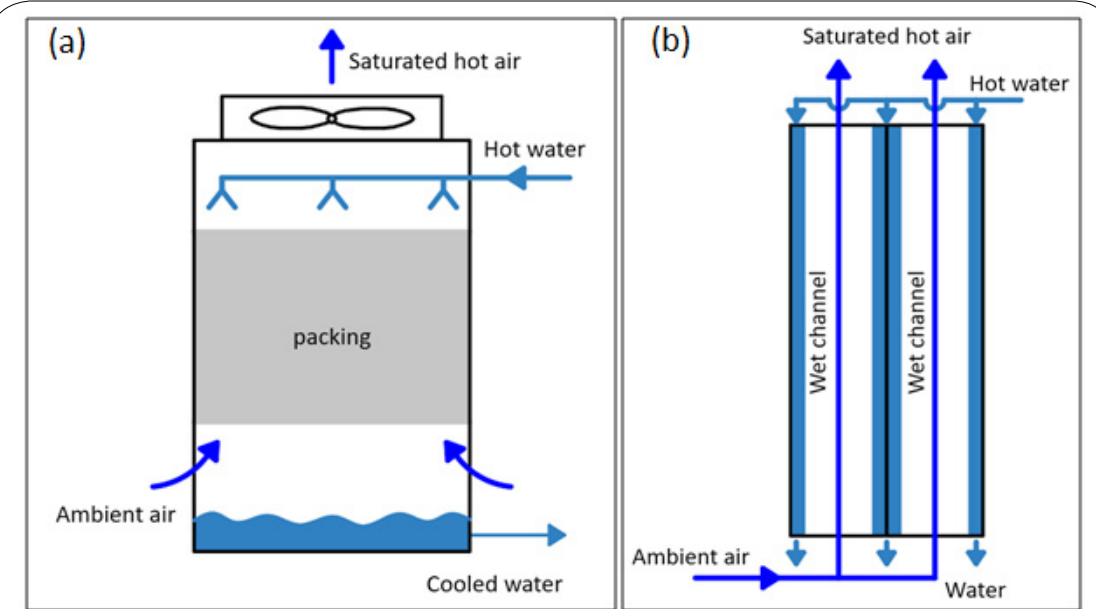

Figure 3: Schematic diagrams (a) General cooling tower scheme. (b) Conventional cooling tower. Reproduced from $[5,6]$.

a)

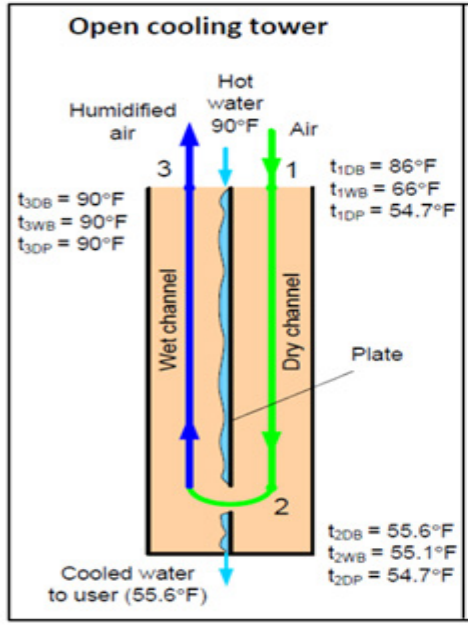

b)

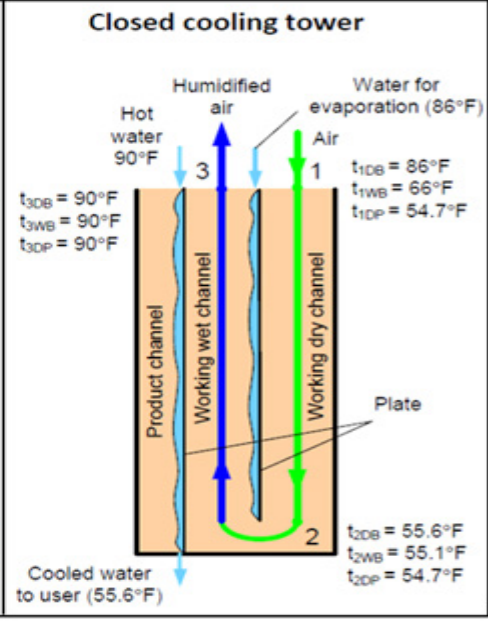

Figure 4: The scheme of the cooling tower through the M-Cycle a) Open circuit M-Cycle cooling tower. b) Closed circuit M-Cycle cooling tower. Reproduced from [5,6].

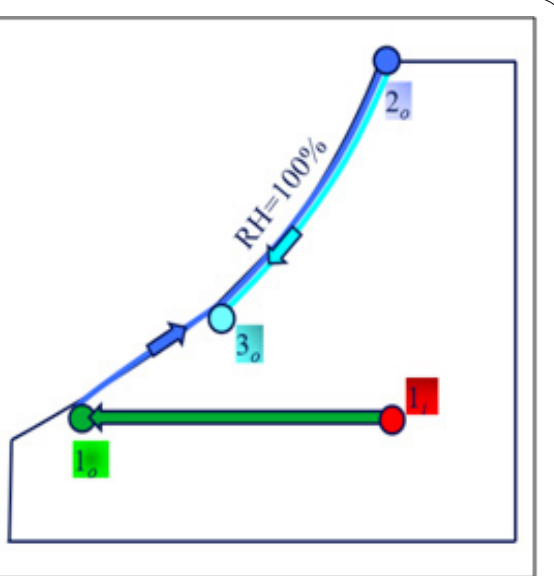

Figure 5: The scheme of distillation through the M-Cycle Unit. 
are for example: reverse osmosis, mechanical vapor compression, vacuum distillation or multistage flash. There is also a possibility to distillate water through the $\mathrm{M}$-cycle technology. The report performed by Gas Technology Institute confirms that the least energy is required to run the distillation process by M-Cycle technology, comparing to reverse osmosis or vapor compression technique. Also operating costs of the M-cycle are the lowest. What is more, to run this process successfully, low grade heat may be used. The distillation process through the M-Cycle presented in Figure 5 is as follows. In first step, the ambient air is delivered to the dry channel ( $\left.1_{i}\right)$ (as an air product) in which it is precooled. After that, the air enters the working channel with porous plate filled with waste water (salty water). In this channel, the evaporation process occurs. After that, theair is delivered to the third condensing channel. Due to condensation process, water may be collected in a tank and directed to reuse.

\section{M-Cycle Combustion Turbine}

Open cycle gas turbine operating on Brayton cycle consists of: a compressor, a combustion chamber, a turbine and a generator (see Figure 6). Brayton Cycle describes constant pressure heat engine. The detail operational principle can be found in the Reference [10]. The gas turbine, using air-water mixture as working fluid, is able to obtain high electric efficiency and high specific power output with investment cost lower than the one of combined cycles [11,12,]. As per the literature, there is plenty of humidified gas turbine cycles, but only few are available commercially. There are key features of humidified gas turbine. Humidification of air before it enters the combustion chamber increases a mass flow rate passing through the turbine and that is why a specific power output is also increased. Moreover, an addition of water reduces the compressed air temperature at the inlet to the recuperator. It gives higher temperature difference what provides the improvement of heat recovery rate. Finally, saturated gas turbine working fluid decreases $\mathrm{NO}_{\mathrm{x}}$ formation during the combustion process [2]. Maisotsenko gas turbine gas been proposed by many authors $[13,14,15]$. In this study the M-Cycle gas turbine based on the Brayton Cycle is described.

The main idea of M-cycle application for Brayton Cycle (Figure 6) is to precool the air in M-Cycle unit before it enters the compressor It allows to decrease air density, and less work is needed to compress the air. That is why more electricity may be produced, hence the turbine effectiveness is higher. In system presented in Figure 6 there is also the second M-cycle unit called "Humidifying Recuperator" in which air is humidified after the compressor and heated before it enters the combustion. Because of gas turbine working fluid enthalpy increment, less fuel is utilized in burning process. It was confirmed by Khalitov et al. that the cycle efficiency may reach even $55 \%$ [16]. Due to great amount of water vapor in the air for combustion, $\mathrm{NO}_{\mathrm{x}}$ pollution is minimalized. On the other side of recuperator, the heat from the exhausted gases is transferred to the gas turbine working fluid. After burning process the air consists of much water vapor. While it contacts with the cold plate of the heat exchanger, the condensation process starts and water can be recovered. It may be summed up that recovered water delivered to the M-Cycle devices reduces the compressor work (see Figure 6).

\section{Future Research Direction for M-Cycle}

There are some potential M-Cycle applications which may be studied in the future. Those are:

1. High pressure-high temperature condensers,

2. Vehicle cooling including engine and cab or solar power systems.

3. Super boilers

4. Heat pump systems

Such as gas turbine engines, water distillation systems and internal combustion engines they need a proper research proven by experimental data. That is why a great work has to be done to successfully implement those ideas in technology.

\section{Summary and Conclusions}

The M-Cycle technology is a thermodynamic process which allows to cool the ambient air or water to the dew-point temperature. Nevertheless, the application of the M-cycle expands in different technologies in which heat recovery is used. In typical cooling applications, the wet-bulb effectiveness of M-Cycle devices is up to 1.80 , whereas for conventional indirect evaporative coolers it may reach 1.0. Cooling towers through the M-Cycle also allow to reduce

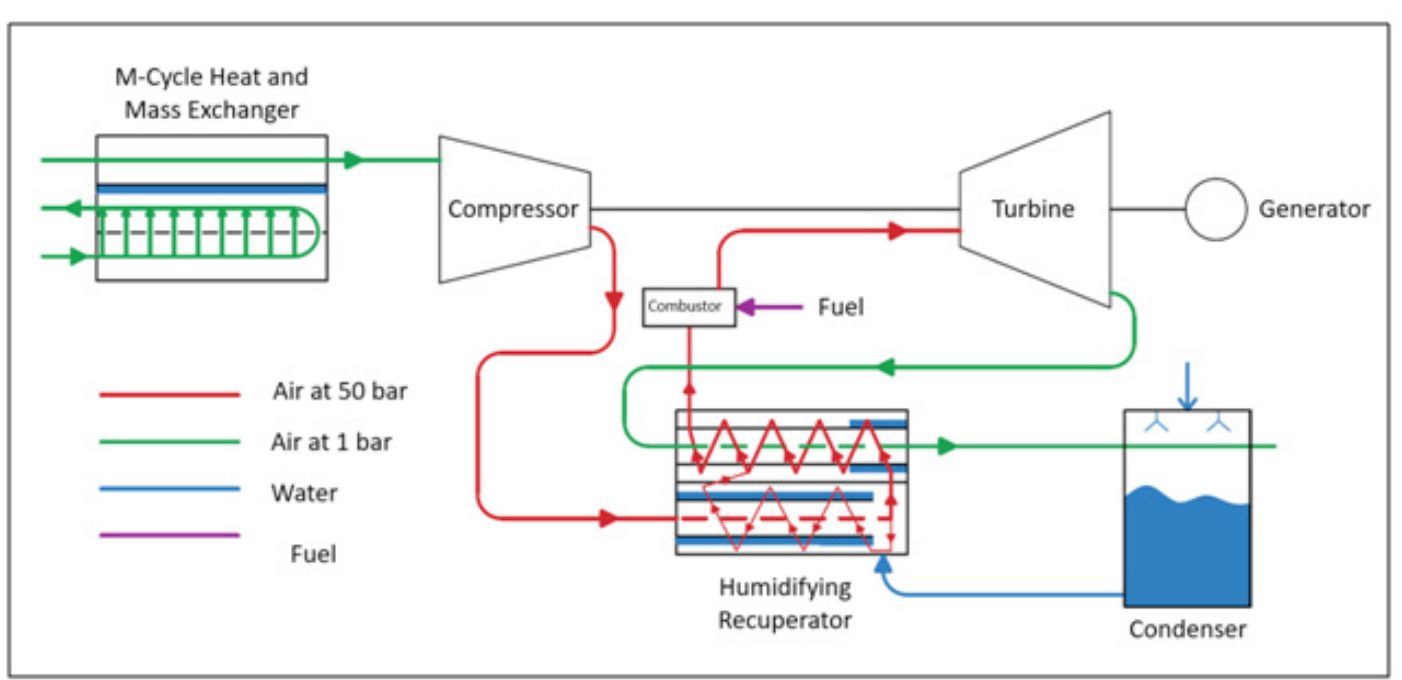

Figure 6: M-Cycle Combustion turbine. 
Citation: Pandelidis D, Pacak A, Anisimov S (2018) Energy Saving Potential by Using Maisotsenko-Cycle in Different Applications. Int J Earth Environ Sci 3: 159. doi: https://doi.org/10.15344/2456-351X/2018/159

Page 5 of 5

water temperature below the wet-bulb temperature to dew point temperature, while in conventional cooling towers it is impossible. M-Cycle technology also gives a possibility of energy and running costs reduction for desalination processes. It may be achieved by special M-Cycle heat and mass exchangers arrangement. Finally, the combustion turbine with two M-cycle devices yield the significant improvement in thermodynamic efficiency of the cycle as compared to typical gas turbine cycles. It follows from the fact that M-cycle technology, using recovered water from exhausted gases, provides cooled air delivered to the compressor and hot humidified air to the combustion. What is more, $\mathrm{M}$-cycle turbines provide pollution control by reducing the amount of $\mathrm{NO}_{\mathrm{x}}$ in exhausted gases.

Nevertheless, it has to be mentioned that experimental researches on M-cycle applications are still limited. That is why this technology still needs development and a lot of research has to be done to find the optimum performance of M-cycle for applications such as distillation, combustion turbine or cooling towers.

\section{Competing Interests}

The authors declare that they have no competing interests.

\section{References}

1. The future of cooling-Report (2018) International Energy Agency.

2. Mahmood MH, Sultan M, Koyama TMS, Maisotsenko VS (2016) Overview of the Maisotsenko cycle-A way towards dew point evaporative cooling. Renewable and Sustainable Energy Reviews 66: 537-555.

3. Anisimov S, Pandelidis D, Danielewicz J (2014) Numerical analysis of selected evaporative exchangers with the Maisotsenko cycle. Energy Convers Manag 88: 426-441.

4. Tyagi SK, Pandey AK, Pant PC, Tyagi VV (2012) Formation, potential and abatement of plume from wet cooling towers: A review. Renew Sustain Energy Rev 16: 3409-3429.

5. Anisimov $S$, Kozlov A, Glanville $P$, Khinkis $M$, Maisotsenko $V$, et al (2014) Advanced Cooling Tower Concept for Commercial and Industrial Applications. Proc ASME PowerConf, Maryland, USA: ASME.

6. Khalatov A, Karp I, Isakov B (2011) Prospects of the Maisotsenko thermodynamic cycle application in Ukraine. Int J Energy Clean Environ 12: 141-157.

7. Gillan L, Glanville P, Kozlov A (2011) Maisotsenko-Cycle Enhanced Cooling Towers. Proc Cool Technol Inst Annu Conf, Texas, USA: Cooling Technology Institute.

8. Morozyuk T, Tsatsaronis G (2011) Advanced cooling tower concept based on the Maisotsenko-cycle-an exergetic evaluation. Int J Energy Clean Environ 12: 159-173.

9. Sverdlin B, Tikhonov A, Gelfand R (2011) Theoretical possibility of the Maisotsenko cycle application to decrease cold water temperature in cooling towers. Int J Energy Clean Environ 12: 175-185.

10. Yee SK, Milanovic JV, Hughes FM (2008) Overview and comparative analysis of gas turbine models for system stability studies. IEEE Trans Power Syst 23: $108-118$.

11. Jonsson M, Yan J (2005) Humidified gas turbines-a review of proposed and implemented cycles. Energy 30: 1013-1078.

12. Poullikkas A (2005) An overview of current and future sustainable gas turbine technologies. Renew Sustain Energy Rev 9: 409-443.

13. Saghafifar M, Gadalla M (2015) Innovative inlet air cooling technology for gas turbine power plants using integrated solid desiccant and Maisotsenko cooler. Energy 87: 663-677.

14. Saghafifar M, Gadalla M (2015) Analysis of Maisotsenko open gas turbine power cycle with a detailed air saturator model. Appl Energy 149: 338-353.

15. Saghafifar M, Gadalla M (2015) Analysis of Maisotsenko open gas turbine bottoming cycle. Appl Therm Eng 82: 351-359.
16. Khalatov AA, Severin SD, Brodetsky PI, Maisotsenko VS (2015) Brayton's subatmospheric inverse cycle with regeneration of output heat by Maisotsenko's cycle. Reports of the National Academy of Sciences of Ukraine 1: 72-79. 